\title{
Global Response in Blood
}

National Cancer Institute

\section{Source}

National Cancer Institute. Global Response in Blood. NCI Thesaurus. Code C159969.

Criteria for the response to treatment in blood, as a component of global response. 